\title{
Indigenous Peoples, Data Sovereignty, and Self-Determination: Current Realities and Imperatives
}

\section{Chidi Oguamanam}

Professor, Faculty of Law, University of Ottawa; Senior Fellow, Centre for International Governance Innovation (CIGI), Waterloo, Canada; and Steering Committee Member, Open African Innovation Research (Open AIR) network

iD https://orcid.org/0000-0003-4301-9388

\begin{abstract}
This study explores the current state and dynamics of the global Indigenous data sovereignty movement - the movement pressing for Indigenous peoples to have full control over the collection and governance of data relating to their lived realities. The article outlines the movement's place within the broader push for Indigenous self-determination; examines its links to big data, open data, intellectual property rights, and access and benefit-sharing; details a pioneering assertion of data sovereignty by Canada's First Nations; outlines relevant UN and international civil society processes; and examines the nascent movement in Africa. The study identifies a fundamental tension between the objectives of Indigenous data sovereignty and those of the open data movement, which does not directly cater for Indigenous peoples' full control over their data. The study also identifies the need for African Indigenous peoples to become more fully integrated into the global Indigenous data sovereignty movement.
\end{abstract}

\section{Keywords}

Indigenous peoples, data, data sovereignty, self-determination, decolonisation, research, data collection, big data, open data, open science, access and benefit sharing (ABS), intellectual property (IP), UN, UNDRIP, CARE principles, FAIR principles, international, CANZUS, Africa

\section{Acknowledgements}

The author thanks University of Ottawa JD student Kelsea Gillespie for research assistance, and the multiple anonymous peer reviewers for their inputs. The author also thanks the internal reviewers at the Centre for International Governance Innovation (CIGI).This article was written as part of the author's participation in the Open African Innovation Research (Open AIR) network. Open AIR is a partnership between the University of Cape Town, the University of Johannesburg, Strathmore University in Nairobi, the Nigerian Institute of Advanced Legal Studies, The American University in Cairo, and the University of Ottawa. The author acknowledges the support currently provided to Open AIR by the Social Sciences and Humanities Research Council (SSHRC) of Canada and the International Development Research Centre (IDRC). This article draws on elements from Oguamanam (2018; 2019). 
DOI: https://doi.org/10.23962/10539/30360

\section{Recommended citation}

Oguamanam, C. (2020). Indigenous peoples, data sovereignty, and self-determination: Current realities and imperatives. The African Journal of Information and Communication (AJIC), 26,1-20. https://doi.org/10.23962/10539/30360

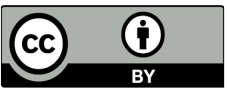

This article is licensed under a Creative Commons Attribution 4.0 International (CC BY 4.0) licence: https://creativecommons.org/licenses/by/4.0

\section{Introduction}

International policy endeavours in support of the world's Indigenous peoples are framed around advancing active Indigenous participation in development pursuits within culturally respectful frameworks. The overarching objectives of these endeavours are geared towards Indigenous self-determination and mechanisms for measuring progress towards this self-determination (see Oguamanam, 2004). Colonial and post-colonial settler states and unitary states have tended, in service to their vested interests, to turn questions of Indigenous self-determination into sites of interminable interpretational somersaulting and foot-dragging (see Dalton, 2005).

In recent years, however, there has been a shift towards more encouraging state efforts to make space for the emergence of self-determined Indigenous development in diverse spheres pursuant to decolonisation and anti-racist agendas. This article focuses on a key element of this trend: the global Indigenous data sovereignty movement, which is pressing for all Indigenous peoples to have full control over the collection and governance of data relating to their communities. The next section sets out Indigenous data sovereignty's conceptual and practical elements, including its interfaces with big data and open data, and its links to matters of intellectual property and access and benefit sharing. The article then moves on to examine a pioneering realisation of data sovereignty, in respect of health information, by Canada's First Nations, followed by an outline of international responses and processes, including the strong role being played by Indigenous peoples in the CANZUS states (Canada, Australia, New Zealand, United States), and conjecture on Africa's place in the global Indigenous data sovereignty movement. 


\section{Conceptual and practical context}

\section{Indigenous data sovereignty}

Data sovereignty denotes the right of states, in relation to other states or entities, "to govern the collection and ownership [of data], including access and use of data that is domiciled within their jurisdiction"(Oguamanam, 2018, p. 207).Data sovereignty, as an idea, is the assumption of responsibility to ensure that information is managed in ways "consistent with the laws, practices, and customs of the nation-state in which it is located" (Snipp, 2016, p. 39). Taking into consideration the sophistication of current technological interventions in data generation and storage, as well as the complex chains of data migration and data valourisation, it can now be persuasively argued that data sovereignty extends to the interest of states in the sanctity, integrity, and security of data - and of the cultural and other contextual sensitivity associated with data. In the words of Schultz and Rainie (2014, p. 1), "[d]ata is intimately linked to the sovereignty and self-determination of all nations".

Under colonial, neo-colonial, and unitary national frameworks, Indigenous peoples have had a troubled relationship with how data concerning them is generated, accessed, shared, applied, and owned. The data has typically been owned by the state in which Indigenous peoples are embedded, or by other non-Indigenous actors, particularly researchers and corporations. Indigenous peoples and their political entities have only comparatively recently begun staking their claims in the data space, as part of their quest for greater self-determination and, in the settler CANZUS states, as part of the broader decolonisation project (see, for example, Open North \& BCFNDGI, 2017).

Indigenous peoples lament that they have been "researched to death", resulting in an extensive trail of abuses and victimisation in research contexts (see American Indian Law Centre, 1999; Blair, 2015; Goodman et al., 2018; Porro et al., 2015). Research is a systemic exercise in gathering and using information to arrive at specific conclusions for the advancement of knowledge and the making of policy. The default until relatively recently was that Indigenous peoples were passive objects and subjects of research funded by non-Indigenous entities and often conducted by academic researchers who may have had complicit relationships with corporations and other institutional actors in the data-generating space. Indigenous peoples did not set the research agendas, as those were predetermined without consultation or without their free, prior, and informed consent (FPIC). One particularly stark example of Indigenous peoples being framed as passive research subjects was the Human Genome Diversity Project, in which the research initially, before protests emerged from Indigenous and other activists, intended to extract human genetic material from Indigenous communities without their informed consent (see Amani \& Coombe, 2005).Sterling (2011), Santos (2008), and Brower (1997) have also shed light on the abuse of Indigenous peoples in human genetic research. 
The undergirding development paradigm and framing of issues in research and data generation relating to Indigenous peoples have typically been culturally insensitive and delivered in top-down, prescriptive modalities. Knowledge arising from research has been valourised as a capitalist proprietary enterprise because " $t]$ here is no law or concept in Western society that recognizes inherent community rights and interests in data and information" (FNIGC, 2016, p. 141). Until recently, rarely did the importance of the interface between personal and collective or community agency resonate in non-Indigenous research paradigms. Furthermore, given the small size of many Indigenous communities, their demographic statistics were seldom reflected in national surveys (Schultz \& Rainie, 2014).

Indigenous peoples are unequivocal that prevailing architectures for research and data generation in their territories have generally been ill-suited to their development aspirations and contradict their objectives of self-determination and self-governance. ${ }^{1}$ While there have been significant efforts to treat research involving Indigenous peoples as a sui generis category (see Government of Canada, 2018), and to adjust institutional review and ethical clearance procedures to this end, matters of collecting, processing, and publishing data on or from Indigenous people are still often negotiated from non-Indigenous perspectives, without tackling questions of cultural sensitivity, sovereignty, and self-determination (Harding et al., 2012).

The Indigenous data sovereignty movement seeks to rectify the relationship between Indigenous peoples and Indigenous data. As Rainie et al. (2019) write,

[Indigenous data sovereignty] refers to the right of Indigenous peoples to govern the collection, ownership, and application of data about Indigenous communities, peoples, lands, and resources. Indigenous data is [...] data in a wide variety of formats inclusive of digital data and data as knowledge and information. It encompasses data, information, and knowledge about Indigenous individuals, collectives, entities, lifeways, cultures, lands, and resources. (Rainie et al. 2019, p. 301)

In the words of the Global Indigenous Data Alliance (GIDA, n.d.),

While the term Indigenous Data Sovereignty is relatively new, Indigenous Peoples have always been data collectors and knowledge holders. The rise of national Indigenous Data Sovereignty networks reflects a growing global concern about the need to protect against the misuse of Indigenous data and to ensure Indigenous Peoples are the primary beneficiaries of their data. (GIDA, n.d.)

1 For a comprehensive literature review of Indigenous peoples' troubled experiences with the conduct of research, see Ermine et al. (2004). 
Misuse of Indigenous data strikes at the core of the ability of Indigenous peoples to exercise their rights to self-determination. Authentic data can drive policy formulation, decision-making, mapping of development aspirations, problem-solving, and other calculations critical to Indigenous empowerment for development in a range of fields. These fields include education, language, finance, health, medicine, agriculture, environmental stewardship, community membership, lands, resources, artworks, rituals, ceremonies, cultural expressions, creativity, and innovation.

\section{Big data and open data}

Big data is massive-volume, high-velocity and high-variety information assets (Corrales et al., 2017; Lefèvre, 2018) on a scale beyond the capacity of conventional or isolated data processing applications, and convertible into diverse and far-reaching uses by powerfully endowed entities. Those entities, which include governments and large private-sector actors, are capable of using a wide variety of high-tech advancements to exploit big data. Meanwhile, open data approaches to big data are part of the "openness or open access movement and its continuing metamorphosis as a malleable approach toward enhancing the flow of information, reducing the costs of its access and optimizing its public impact in contrast to a closed proprietary approach" (Oguamanam, 2018).

Big data and open data have "a nuanced relationship" (Oguamanam, 2018, p. 200), in that they "are constructive and modified forms of proprietary [i.e., exclusive and commercial] use of data in self-interested ways that strategically [encourage] target forms of sharing via licencing or related schemes to optimize value" (Oguamanam, 2018,pp.199-200). They are phenomena that each — and sometimes in combinationhave the potential to be beneficial to Indigenous data sovereignty. For example, open data, with or without big data, can allow Indigenous peoples to engage in shared or collaborative uses of data across geographically dispersed nations and communities. Yet at the same time, big and open data phenomena reflect the complex interests and divergent stakeholders that operate in the data space, and those interests tend to be aligned neither with Indigenous peoples nor with the raison dêtre of Indigenous data sovereignty. Clearly, "[t]he global data revolution and associated new technologies can be a double-edged sword for indigenous peoples if the values and principles of indigenous data sovereignty are not respected" (Open North \& BCFNDGI, 2017, p. 7). What is often not mentioned is that, for reasons of sacralisation and other cultural considerations, not all forms of information or knowledge relating to Indigenous peoples are open to reduction into data or exposure to the public domain in the conventional sense. 
A core instrument in the open data movement is the 2015 International Open Data Charter (ODC), which begins with the statement that "[o]pen data is digital data that is made available with the technical and legal characteristics necessary for it to be freely used, reused, and redistributed by anyone, anytime, anywhere" (Open Data Charter, 2015). While there is much that is laudable in this statement and the others in the ODC, the instrument does not, in its current form, take cognisance of the requirements of Indigenous data sovereignty. As Rainie et al. (2019) write, the ODC's call for data's free use, reuse, and redistribution "by anyone, anytime, anywhere" is "in direct tension with the rights of Indigenous peoples to govern their data, including the right to decide what is shared or withheld, likely resulting from the ODC being developed without the involvement of Indigenous peoples" (Rainie et al., 2019, p. 301).

It is necessary to ensure that big data and open data approaches are understood and applied by nation states and other stakeholders in ways that, in the words of Open North and BCFNDGI (2017, p. 6), do not "further marginalize/reinforce structural oppression toward Indigenous Nations." According to Lauriault (2017), as quoted in Oguamanam and Jain (2017), the "open data community needs to critically reflect on its worldview and how it differs from that of Indigenous People". There is evidence to suggest that this point is not lost on certain big data and open data players. For example, Open North, a global big data entity, is actively involved with Canadian Indigenous people in efforts to foster Indigenous data sovereignty in ways that critically account for its relationship with open data and its underlying parameters (Open North \& BCFNDGI, 2017).

\section{IP and $A B S$}

The question of how Indigenous data sovereignty protocols (e.g., the OCAP framework that is discussed below) deal with non-Indigenous use of Indigenous data is crucially important. And among the most egregious abuses of Indigenous knowledge by non-Indigenous actors are those perpetrated via the application of intellectual property (IP) rights-for example, via private-sector patenting, without FPIC, of pharmaceuticals, nutraceuticals and agricultural or food products developed with the use of Indigenous knowledge and/or genetic resources sourced from Indigenous lands.

Central to IP questions, and to Indigenous data sovereignty, are matters of access and benefit sharing $(\mathrm{ABS})$ in respect of genetic resources on Indigenous lands, and the associated Indigenous knowledge (Robinson, 2010; 2014). The evolution of ABS has resulted in the reinforcement of valuable consent principles such as the aforementioned FPIC - through which, when IP rights are sought, there must be documentation of the source and origin of the genetic resources being acquired for research and, where applicable, a resulting invention or innovation (Robinson et al., 2017). ABS is a traction point for underscoring how biotechnology and Indigenous 
ecological (or biocultural) knowledge constitute one of the core intersection points in the data sovereignty domain. In order for Indigenous peoples to be able to effectively participate in $\mathrm{ABS}$, it is imperative that they have control over the data representations of their genetic resources and associated Indigenous knowledge.

One way in which Indigenous data can be harnessed in a manner that mitigates the potential for IP and ABS abuses is compilation of Indigenous knowledge into online databases that make clear the provenance of the knowledge. A pioneering initiative of this kind is India's Traditional Knowledge Digital Library (TKDL), established in 2001 by the Indian Government's Council of Scientific and Industrial Research (CSIR). The TKDL project has "structured and classified the Indian Traditional Medicine System [...], thus enhancing the quality of search and examination of prior art with respect to patent applications [...] in the area of traditional knowledge" (TKDL, n.d.). The Indigenous knowledge documented in the TKDL is made available to patent offices around the world, so as to both "protect Indian traditional medicinal knowledge" and "prevent its misappropriation [through unjust patenting]" (TKDL, n.d.). The presence of the TKDL has already resulted in more than 200 patent applications being rejected, withdrawn, or revised (TKDL, n.d.).

\section{A pioneering national response: Canada's First Nations and the OCAP principles}

In 1994, the Government of Canada, through Health Canada and its then-named Medical Services Branch, launched three nationwide longitudinal health surveys. The initiative excluded most members of Canada's First Nations. (The First Nations, with the Inuit and Métis, constitute the country's Indigenous peoples.) In an effort to address this gap, in 1995 the Medical Services Branch extended an invitation to regional First Nations representatives to participate in a supplementary survey. This invitation came at a time when, as explained by the First Nations Information Governance Centre (FNIGC), "the issue of First Nations jurisdiction over all matters including ownership of information was at the forefront of First Nations political thinking" (FNIGC, 2016, p. 146). Emblematic of the prominence of the issue at the time is the 1996 Report of the country's Royal Commission on Aboriginal Peoples (RCAP), which pointed to the fact that information-gathering on Indigenous people is typically conducted without considering the peoples' concerns and priorities (RCAP, 1996).

In response to the aforementioned government invitation to participate in a supplementary health survey, in 1997 the First Nations constituted a committee (the precursor to today's FNIGC) that conducted and delivered the inaugural First Nations Regional Health Survey (RHS) (FNIGC, 2016). The data collected through 
this exercise was, according to the FNIGC, "invaluable, helping to generate program resources in several key public and community health areas" (FNIGC, 2016, p. 147). In addition,

First Nations were acutely aware of the opportunity to utilize the RHS as a vehicle to move the benchmark ahead in favour of First Nations' data jurisdiction and ensure the continued forward momentum of sovereignty over data information, knowledge and stories. It was from the works of the RHS that the concepts inherent to data jurisdiction were articulated. (FNIGC, 2016, p. 147)

The RHS is now undertaken every four years in Canada, and Canadian Indigenous peoples' participation is backed by the FNIGC-developed (and trademarked) ownership, control, access, and possession (OCAP) governance principles (FNIGC, n.d.). OCAP "represents principles and values that are intertwined and reflective of First Nations' views of jurisdiction and collective rights" (FNIGC, 2016, p. 149), and is institutionally administered by the FNIGC. According to the FNIGC, the RHS represents

the first national survey to be fully owned, controlled and stewarded by First Nations. Nothing like it had ever been successfully completed anywhere in the world. Concepts such as full ownership of data and intellectual property by First Nations, First Nations stewardship of data and government access through a limited licence to use were to become essential elements of the original RHS and form the backbone of $\mathrm{OCAP}^{\circledR}$ principles as they exist today. (FNIGC, 2016, p. 146)

The First Nations' experience in Canada with the RHS is an "illustration of how sovereignty can be realized in relation to data, information and knowledge as part of a broader goal of self-determination" (Kukutai \& Taylor, 2016, p. 9). Since its first implementation in 1997, the RHS has served as one of the beacons in the global Indigenous movement towards data sovereignty.

\section{International responses and processes}

\section{UNPFII and UNDRIP}

A key milestone during the first UN International Decade of the World's Indigenous People (1995-2004) was the establishment in 2000 of the UN Permanent Forum on Indigenous Issues (UNPFII), ${ }^{2}$ a high-level advisory body to the UN Economic and

2 Establishment of a Permanent Forum on Indigenous Issues, ECOSOC Res 2000/22, UNECOSOCOR, 45th Sess, UN Doc E/RES/2000/22 (2000). 
Social Council (ECOSOC). Through ECOSOC, the UNPFII's opinions and recommendations are channelled to specific UN programmes, funds, and agencies for implementation and translation into policy. The UNPFII's work and mandates focus on six thematic areas, namely: economic and social development, culture, the environment, education, health, and human rights. In 2001, a year after the UNPFII was established, the UN Commission on Human Rights appointed a Special Rapporteur on the rights of Indigenous peoples. ${ }^{3}$

Six years later, in 2007, the UN adopted its Declaration on the Rights of Indigenous Peoples (UNDRIP) (UN, 2007a). In the same year, the UN Human Rights Council established the Expert Mechanism on the Rights of Indigenous Peoples (EMRIP) (UN, 2007b), which was tasked, pursuant to UNDRIP, with providing expertise and advice to the Human Rights Council. ${ }^{4}$ The UNPFII, the Special Rapporteur, and EMRIP are, thus, the three main bodies in the UN system with special mandates that directly focus on Indigenous issues, with UNDRIP serving as the framing instrument.

An enduring objective of the Indigenous data sovereignty movement is advancing the rights enunciated in UNDRIP, including its unequivocal stance on the right of Indigenous peoples to self-determination. Specifically, Article 3 of UNDRIP provides that "Indigenous Peoples have the right to self-determination. By virtue of that right they freely determine their political status and freely pursue their economic, social and cultural development". And Article 31 of UNDRIP takes an omnibus and summative approach to the protection of Indigenous rights, declaring that:

Indigenous Peoples have the right to maintain, control, protect, and develop their cultural heritage, traditional knowledge, and traditional cultural expressions, as well as the manifestations of their sciences, technologies, seeds, medicines, knowledge of properties of flora and fauna, sports and traditional games, visual and performing arts. They also have the right to maintain, control, protect and develop their intellectual property over such cultural heritage, traditional knowledge and traditional cultural expressions.

The UNPFII has devoted a significant portion of its work to the promotion of data sovereignty as part of its support for the right of self-determination unequivocally affirmed in UNDRIP. Among other things, the UNPFII pursues Indigenous data sovereignty as a means of ensuring accurate demography and enumeration in Indigenous communities and, in turn, better aggregation of Indigenous information

3 The first Special Rapporteur on the rights of Indigenous peoples was Mexico's Rodolfo Stavenhagen, appointed in 2001.

4 The UNDRIP resolution was passed in September 2007 and the EMRIP resolution was passed in December 2007. 
towards the measurement and evaluation of progress or lack thereof regarding UNDRIP and UN programmes that engage Indigenous peoples. The UNPFII's work in the area of data derives from its mandate 2(c), in terms of which it is required to "prepare and disseminate information on Indigenous issues". ${ }^{5}$ At its first session in 2004, the UNPFII convened an Expert Workshop on Data Collection and Data Aggregation for Indigenous Peoples (UNPFII, 2004). As explained by Gilbert and Lennox (2019), this workshop established the following core principles:

\begin{abstract}
[...] all data collection should follow the principles of FPIC [free, prior and informed consent]; the principle of self-identification should be paramount in determining subjects/categories of data collection; participation of indigenous peoples in the collection process is essential; and moreover, 'data collection must respond to the priorities and aims of the indigenous communities themselves'. (Gilbert \& Lennox, 2019, p. 112)
\end{abstract}

In 2006, the UNPFII convened another data-focused workshop, which recommended, inter alia, that the UN "identify and adopt appropriate indicators of indigenous identity, lands, ways of living, and indigenous rights to, and perspectives on, development and well-being" (UNPFII, 2006). In the years since these 2004 and 2006 workshops on data collection and aggregation, the UNPFII has consistently placed Indigenous data issues at the core of $\mathrm{UN}$ development planning and implementation across numerous programmes, funds, and agencies (see Gilbert \& Lennox, 2019). In turn, a wide range of other key international actors, including the World Bank, the International Finance Corporation, corporations, donors, and development agencies have come to recognise Indigenous-sanctioned data as being crucial to legitimate and informed insights into matters of Indigenous peoples' self-determination and development.

\title{
UN World Conference on Indigenous Peoples, IPMG
}

The outcome document of the 2014 high-level plenary meeting of the UN General Assembly, also known as the World Conference on Indigenous Peoples, provides in paragraph 10 that:

[w] commit ourselves to working with indigenous peoples to disaggregate data, as appropriate, or conduct surveys and to utilizing holistic indicators of indigenous peoples' well-being to address the situation and needs of indigenous peoples and individuals, in particular older persons, women, youth, children and persons with disabilities. (UN General Assembly, 2014)

5 Establishment of a Permanent Forum on Indigenous Issues, ECOSOC Res 2000/22, UNECOSOCOR, 45th Sess, UN Doc E/RES/2000/22 (2000). 
Data on Indigenous peoples is integral to the UN's 2015 resolution, Transforming Our World: The 2030 Agenda on Sustainable Development (UN, 2015) and the 17 accompanying Sustainable Development Goals (SDGs), as adopted in 2015, with the UNPFII succeeding in ensuring that Indigenous-related data is "a key strand" of the SDGs (Gilbert \& Lennox, 2019, p. 10), and that the resolution states "the need for the participation of Indigenous peoples at the country level and [...] for disaggregated data on Indigenous status on Indigenous peoples' terms" (Rainie et al., 2019, p. 306).

The key entity for Indigenous peoples within the SDG process is the Indigenous Peoples Major Group for Sustainable Development (IPMG), which is a strong champion for the use of Indigenous data in the SDG implementation, monitoring, and evaluation processes. The IPMG is one of the eligible participating major groups in the SDG process (see Gilbert \& Lennox, 2019; IPMG, n.d.). The group was proactive via a position paper it prepared for the proposed SDGs in which it advocated a monitoring and evaluation framework for gauging the impact of SDGs on Indigenous peoples and issues, especially the right to self-determination (IPMG, 2015).

\section{UN CBD and Nagoya Protocol}

Another UN instrument with great relevance to Indigenous data sovereignty is the 1992 Convention on Biological Diversity (CBD) (UN, 1992). Generally, the CBD and its 2010 Nagoya Protocol on Access and Benefit Sharing brought access to genetic resources, and to associated Indigenous or traditional knowledge, within a framework of fair and equitable sharing of benefits arising from the resources' utilisation. The Nagoya Protocol has a broad definition of "utilization of genetic resources", primarily focused on the context of research and development (R\&D) in biotechnology (UN, 2010, Art. 2(c)). The CBD's definition of biotechnology refers to "any technological application that uses biological applications, living organisms and derivatives thereof, to make or modify products or processes for specific use" (UN, 1992, Art. 2). Derivatives are defined under the Nagoya Protocol as "naturally occurring biochemical compounds resulting from the genetic expression or metabolism of biological or genetic resources, even if [they do] not contain functional units of heredity" (UN, 2010, Art. 2(e)).

Both the CBD and its Nagoya Protocol are, on the face of it, oriented towards physical dealings with-i.e., use and transfer of - genetic resources. Within this orientation, matters of the provenance or origin of genetic resources (and associated Indigenous knowledge, where applicable) and of ensuring FPIC are relatively straightforward (Oguamanam, 2018, p. 198). However, there are today myriad applications of digital information and communication technologies (ICTs) in R\&D relating to genetic resources, including resources in which associated Indigenous knowledge is also implicated. This transformation in R\&D relating to genetic resources is animated 
through disciplinary convergences across, inter alia, bioinformatics, synthetic biology, digital sequencing, and artificial intelligence (AI) or machine learning. These ICT applications provide increasingly wide amplitude for generating, processing, and reducing genetic resources and associated Indigenous knowledge into digital, virtual datasets that proactively de-link the resources from, inter alia, their provenance in Indigenous and local communities. Such de-linking has ramifications for determining when information or datasets relating to genetic resources interface with Indigenous knowledge and, as such, should have the status of a derivative in relation to any resulting innovation. This determination of derivative status can be central to, inter alia, patenting and other forms of IP protection in relation to genetic resources. At the same time, digital transformations in the biotechnology sphere can have positive ramifications for open science.

Altogether, the aforementioned ICT deployments present both opportunities and challenges for Indigenous data sovereignty. There is, accordingly, a clear imperative for vigilance on the part of Indigenous peoples in respect of how the CBD and its Nagoya Protocol on ABS respond to, or could be interpreted in the light of, the new technological realities in which genetic resources are reduced to malleable and incorporeal datasets.

\section{GIDA and IDSIG}

Indigenous data sovereignty as an Indigenous-driven international initiative is currently led by the Global Indigenous Data Alliance (GIDA) and the International Indigenous Data Sovereignty Interest Group (IDSIG), both of which cooperate with the Research Data Alliance (RDA). IDSIG is an initiative of a tripartite network of national Indigenous organisations: Te Mana Raraunga (the Maori Data Sovereignty Network) in Aotearoa/New Zealand, the US Indigenous Data Sovereignty Network, and the Maiam nayri Wingara Aboriginal and Torres Strait Islander Data Sovereignty Group in Australia (Kukutai \& Taylor, 2016; Oguamanam, 2018). In 2017, IDSIG issued the International Indigenous Data Sovereignty IG Charter Statement, which includes the following statements:

Like other nation states, Indigenous nations need data about their citizens and communities to make informed decisions. However, the information that Indigenous nations have access to is often unreliable, inaccurate, and irrelevant. Federal, state, and local governments have primarily collected these data for their own use. Indigenous nations' reliance on external data that do not reflect the community's needs, priorities, and self-conceptions is a threat to self-determination. The demand for Indigenous data is increasing as Indigenous nations and communities engage in economic, social and cultural development on an unprecedented level. Given the billions of dollars in research funding spent each year and the increasing momentum of the international big data and open data movements, Indigenous nations and communities are uniquely positioned to claim a seat at the ta- 
ble to ensure Indigenous Peoples are directly involved in efforts to promote data equity in Indigenous communities. (IDSIG, 2017)

A 2018 global workshop on "Indigenous Data Sovereignty Principles for the Governance of Indigenous Data", convened by the RDA and International Data Week in Gaborone, Botswana, released what have come to be known as the CARE Principles for Indigenous Data Governance (GIDA, 2019). The CARE principles-collective benefit, authority to control, responsibility, and ethics-are now the guiding principles of the global Indigenous data sovereignty movement being taken forward by GIDA, IDSIG, and the RDA. The principles can be viewed as an effort to, inter alia, temper tendencies among big data, open data, and open science practitioners towards giving short shrift to Indigenous data sovereignty. GIDA sums up the sentiment in the following observation:

The current movement toward open data and open science does not fully engage with Indigenous Peoples rights and interests. Existing principles with the open data movement (e.g. FAIR: findable, accessible, interoperable, reusable) primarily focus on characteristics of data that will facilitate increased data sharing among entities while ignoring power differentials and historical contexts. The emphasis on greater data sharing alone creates a tension for Indigenous Peoples who are also asserting greater control over the application and use of Indigenous data and Indigenous Knowledge for collective benefit. (GIDA, n.d.)

The FAIR principles cited by GIDA in this quoted passage are extolled by the open data movement, and are also consistent with big data and open science paradigms. Indigenous data sovereignty proponents are sceptical about the validity of CARE as a stand-alone set of principles, and hence they insist that there is a need for open data stakeholders, and indeed open science and big data stakeholders, to adhere to both the FAIR and CARE principles as a means of accommodating and accounting for Indigenous data sovereignty.

The CARE framework is oriented towards the collective benefit of Indigenous peoples achieved through the use of data for inclusive innovation and self-determined development. It also supports the authority of Indigenous peoples and institutions to control data relating to their territories, resources, land, knowledge, and language, and to ensure culturally sensitive data governance models, including adherence to FPIC. CARE emphasises both data for governance and governance of data, i.e., both the use of data for advancing Indigenous governance and, at the same time, the use of data in ways that follow data governance protocols appropriate to Indigenous data. CARE also strongly supports ethical considerations across the life cycle of Indigenous data, including reducing real and perceived harms, optimising benefits, and promoting human rights, including the rights espoused in UNDRIP. 


\section{Indigenous Navigator}

Established in 2014, the Indigenous Navigator is "a framework and set of tools for and by indigenous peoples to systematically monitor the level of recognition and implementation of their rights" (Indigenous Navigator, n.d.). The tools can be used to monitor progress towards the Indigenous empowerment and development objectives set out in, inter alia, the SDGs, UNDRIP, and the World Conference on Indigenous Peoples (see Gilbert \& Lennox, 2019). The Indigenous Navigator facilitates the collection of high-quality grassroots and community data that are then fed into the project's online portal.

The Indigenous Navigator's pilot phase was in 2014, and this involved the use of the Navigator to generate quality data relating to progress on Indigenous issues in six countries: Peru, Kenya, Cameroon, Suriname, Thailand, and Nepal. The second phase, launched in 2017, involved 11 countries, including all the countries in the first phase, with the exception of Thailand, and adding Bangladesh, Cambodia, the Philippines, Bolivia, Colombia, and Tanzania.

\section{African responses and processes}

From the foregoing analysis, it is clear that Indigenous data sovereignty has to date been driven to a great extent by activities in CANZUS countries. In Africa, engagement with the global movement has yet to reach critical mass. Among the potential reasons for this slower evolution of the movement in Africa, compared to the CANZUS states, is the very different and ambiguous history of the instrumentalisation of the concept of indigeneity on the continent.

In African countries, indigeneity can be said to have two meanings (see Crawhall, 2011). According to one meaning, all black Africans are Indigenous to Africa. But according to the second meaning, the large and politically powerful ethnic groupings in many sub-Saharan African countries are relatively recent arrivals in the territories they inhabit, having migrated from West Africa and, upon arrival, encountered the Indigenous peoples already living there (Crawhall, 2011). While there has been, and still is, a reluctance by some African governments to champion the rights of Indigenous minorities in their nation states, there was evidence of growing acceptance of Indigenous self-determination among the African diplomats who participated in the development of UNDRIP, a declaration which the vast majority of African UN Member States adopted (Crawhall, 2011; UN, 2007). As Crawhall (2011) explains, central to African states' growing acceptance of Indigenous peoples' rights during the UNDRIP talks was the advocacy work of the Indigenous Peoples of Africa Coordinating Committee (IPACC), a civil society body composed of representatives of Indigenous peoples in numerous African nations. This augurs well for the future of efforts towards Indigenous data sovereignty on the continent. 
Also contributing to the potential for a strong African data sovereignty movement is the robust engagement on the continent with matters of data governance, especially in the context of IP and development narratives, and in specific areas such as agricultural data (see Dagne, 2020). As in many other regions of the world, there is a growing exploration on the continent of elements of "open development" (see Smith \& Seward, 2020) by development funders, development projects, researchers, scholars, and policymakers. The open development framework valourises open collaborative innovation (see Open AIR, n.d.), open data, open science, open access publishing, open government data, open health data, and open educational resources (OER) (Smith \& Seward, 2020). These and similar ideas are finding traction in, and in relation to, African Indigenous and local communities who are largely represented in informal economic sectors.

At the same time, particularly in the context of AI deployments on the continent, there is growing concern about power imbalances between African and foreign participants, leading to complaints of "data colonialism" (see Couldry \& Mejias, 2019). Thus, the opportunities and challenges presented by big data and open data, and their ramifications for the self-determined development of Indigenous peoples, are as real, in Africa, as elsewhere.

In the specific context of Indigenous data sovereignty, it is significant that, as noted earlier, the CARE principles were drafted in Botswana, with active African representation and participation in the drafting. In addition, it is notable that three African countries, namely Kenya, Cameroon, and Tanzania, were participants in the early stages of the operationalisation of the global Indigenous Navigator data platform.

\section{Conclusions}

For self-determined Indigenous development to be of any consequence, it must be rooted in data sovereignty. Put differently, the sine qua non for self-determined development is the unfettered ability of Indigenous peoples to set their own research agenda, frame or design their own research questions, and select their own research partners. Also necessary is the capability of Indigenous peoples to analyse and interpret research results, and to negotiate their applications or outputs as consequential and transformative exercises of self-determined development.

Without question, Indigenous data sovereignty as a theory and practice is a work in progress, with paradigmatic pulls and tensions surrounding it. One core source of paradigmatic pull and tension is the paradoxical role of ICTs. As with virtually all socio-economic realms, ICTs have redefined and emboldened Indigenous interest in data sovereignty. ICTs enhance the ease of sourcing and transferring information, potentially resulting in the intensification of asymmetrical power relations, reminiscent of how colonial states and their agents dealt with Indigenous data. At 
the same time, ICTs have emboldened Indigenous peoples by serving as authentic tools of decolonisation and self-determination-tools that are essential to furthering the advancement of Indigenous data sovereignty. Without introspection or protocols on how ICTs can better serve Indigenous peoples in their quest for data sovereignty, there is the potential for an uncritical embrace that leads to the slippery reductionist slope of technological determinism. Such a tendency would undermine the necessary emphasis on cultural and other contextual variables that are served and preserved by Indigenous data sovereignty vis-á-vis the rapid traction and interest now associated with open data, big data, open science, and related concepts.

A sign of the growing maturity of the Indigenous data sovereignty movement is its increasing emphasis on the need for high-quality data in order for Indigenous peoples to be able to evaluate progress and ensure accountability across development and human rights spectra. This quest for quality is evidenced in, inter alia, the Indigenous Navigator project discussed above. Another sign of the maturing of the Indigenous data sovereignty space is the increasing, albeit late, presence of African players. However, African Indigenous peoples have yet to fully integrate themselves into the global movement, and there is an urgent need for this integration to occur.

\section{References}

Alfred, T., \& Corntassel, J. (2005). Being Indigenous: Resurgences against contemporary colonialism. Government and Opposition, 40(4), 597-614. https://doi.org/10.1111/j.1477-7053.2005.00166.x

Amani, B., \& Coombe, R. (2005). The Human Genome Diversity Project: The politics of patents at the intersection of race, religion, and research ethics. Law $\mathcal{E}$ Policy, 27(1), 152-188. https://doi.org/10.1111/j.1467-9930.2004.00195.x

American Indian Law Centre. (1999). Model tribal research code (with materials for tribal regulation for research and checklist for Indian Health Boards) (3rd ed.). Albuquerque: University of New Mexico.

Anaya, J. (2004). Indigenous peoples in international law. Oxford University Press.

Animikii Indigenous Technology. (2019, June 7). Decolonizing digital: Contextualizing Indigenous data sovereignty. https://www.animikii.com/news/decolonizing-digital-contextualizing-indigenous-data-sovereignty

Blair, N. (2015). Researched to death: Indigenous peoples talkin' up our experiences of research. International Review of Qualitative Research, 8(4), 463-478. https://doi.org/10.1525/irqr.2015.8.4.463

Borrows, J. (2017). Policy paper: Implementing Indigenous self-determination through legislation in Canada. Assembly of First Nations (AFN). https://www.afn.ca/wp-content/uploads/2018/09/2017-04-20-Implementing-Indigenous-self-determination-through-policy-legislation.pdf

Brower, V. (1997). From human rights to the human genome - stopping biopiracy. Nature Medicine, 3(10), 1056. https://doi.org/10.1038/nm1097-1056b 
Corrales, M., Fenwick, M., \& Forgó, N. (Eds.). (2017). New technology, big data and the law. Springer. https://doi.org/10.1007/978-981-10-5038-1

Couldry, N., \& Mejias, U. (2019). Data colonialism: Rethinking big data's relation to the contemporary subject. Television and New Media, 20(4), 336-349.

https://doi.org/10.1177/1527476418796632

Crawhall, N. (2011). Africa and the UN Declaration on the Rights of Indigenous Peoples. The International Journal of Human Rights, 15(1), 11-36. https://doi.org/10.1080/13642987.2011.529687

Dagne, T. (2020). Embracing the data revolution for development: A data justice framework for farm data in the context of African Indigenous farmers. The Journal of Law, Social Justice and Global Development, 25.

Dalton, J. E. (2005). International law and the right of Indigenous self-determination: Should international norms be replicated in the Canadian context? Queen's Institute for Intergovernmental Relations Working Paper No 1. https://dx.doi.org/10.2139/ssrn.932467

Davies, T., Walker, S., Rubinstein, M., \& Perini, F. (Eds.). (2019). The state of open data: Histories and horizons. African Minds and International Development Research Centre (IDRC). https://doi.org/10.47622/9781928331957

Ermine, W., Sinclair, R., \& Jeffery, B. (2004). The ethics of research involving Indigenous peoples. Report of the Indigenous Peoples' Health Research Centre to the Interagency Advisory Panel on Research Ethics. https://www.researchgate.net/publication/317055157_The_Ethics_of_Research_Involving_Indigenous_Peoples

First Nations Information Governance Centre (FNIGC). (n.d.). OCAP. https://fnigc.ca/ ocap

FNIGC. (2016). Pathways to First Nations' data and information sovereignty. In T. Kukutai, \& J. Taylor (Eds.), Indigenous data sovereignty: Toward an agenda (pp. 139-155). ANU Press.

FNIGC. (2020). A First Nations data governance strategy. https://fnigc.inlibro.net/cgi-bin/ koha/opac-retrieve-file.pl:id=9c677f3dcf8adbf18fcda96c6244c459

Geomatics and Cartographic Research Centre (GCRC), \& Canadian Internet Policy and Public Interest Clinic (CIPPIC). (2016). A proposal: An open licensing scheme for traditional knowledge. https://cippic.ca/sites/default/files/file/CIPPIC GCRC--TK License Proposal--July 2016.pdf

Gilbert, J. (2011). Indigenous peoples' human rights in Africa: The pragmatic revolution of the African Commission on Human and Peoples' Rights. International and Comparative Law Quarterly, 60(1), 245-270. https://doi.org/10.1017/S0020589310000746

Gilbert, J., \& Lennox, C. (2019). Towards new development paradigms: The United Nations Declaration on the Rights of Indigenous Peoples as a tool to support self-determined development. International Journal of Human Rights, 23(1-2), 104-124. https://doi.org/10.1080/13642987.2018.1562921

Global Indigenous Data Alliance (GIDA). (2019). CARE principles for Indigenous data governance. https://www.gida-global.org/care

GIDA. (n.d.). History of Indigenous data sovereignty. https://www.gida-global.org/history-of-indigenous-data-sovereignty 
GO FAIR Initiative. (n.d.). FAIR principles. https://www.go-fair.org/fair-principles/

Goodman, A., Morgan, R., Kuehlke, R., Kastor, S., Fleming, K., Boyd, J., \& Aboriginal Harm Reduction Society (2018). "We've been researched to death": Exploring the research experiences of urban Indigenous Peoples in Vancouver, Canada. The International Indigenous Policy Journal, 9(2), 1-20. https://doi.org/10.18584/iipj.2018.9.2.3

Government of Canada. (2018). Tri-Council Policy Statement (TCPS) 2 - Chapter 9: Research Involving First Nations, Inuit and Métis Peoples of Canada. Government of Canada Panel on Research Ethics. https://ethics.gc.ca/eng/tcps2-eptc2 2018 chapter9-chapitre9.html

Harding, A., Harper, B., Stone, D., O’Neill, C., Berger, P., Harris, S., \& Donatuto, J. (2012). Conducting research with tribal communities: Sovereignty, ethics, and data-sharing issues. Environmental Health Perspectives, 120(1), 6-10. https://doi.org/10.1289/ehp.1103904

Indigenous Peoples Major Group for Sustainable Development (IPMG). (n.d.). https://indigenouspeoples-sdg.org/index.php/english/

IPMG. (2015). Indigenous Peoples Major Group position paper on proposed SDG indicators. https://www.indigenouspeoples-sdg.org/index.php/english/all-resources/ipmg-position-papers-and-publications/ipmg-reports

International Indigenous Data Sovereignty Interest Group (IDSIG). (2017). International Indigenous Data Sovereignty IG Charter Statement. https://www.rd-alliance.org/ group/international-indigenous-data-sovereignty-ig/case-statement/international-indigenous-data

Indigenous Navigator. (n.d.). [Website]. https://nav.indigenousnavigator.com/index.php/en/ Kukutai, T., \& Taylor,J. (2016). Data sovereignty for indigenous peoples: Current practice and future needs. In T. Kukutai \& J. Taylor (Eds.), Indigenous data sovereignty: Toward an agenda (pp. 1-22). ANU Press. https://doi.org/10.22459/CAEPR38.11.2016.01

Lauriault, T. P. (2017). Critical data studies, smart cities and precision farming. Presentation to CIPPIC Summer Seminar Series, delivered at the University of Ottawa, 16 May. Unpublished.

Lefèvre, T. (2018). Big data in forensic science and medicine. Journal of Forensic and Legal Medicine, 57,1-6. https://doi.org/10.1016/j.jflm.2017.08.001

Lovett, R., Lee, V., Kukutai, T., Cormack, D., Rainie, S. C., \& Walker, J. (2019). Good data practices for Indigenous data sovereignty and governance. In A. Daly, S. K. Devitt, \& M. Mann (Eds.), Good data (pp. 26-36). Institute of Network Cultures. https:// researchcommons.waikato.ac.nz/handle/10289/12919

Marx, L., \& Smith, M. R. (Eds.). (1994). Does technology drive history? The dilemma of technological determinism. MIT Press.

McMahon, R., LaHache, T., \& Whiteduck, T. (2015). Digital data management as Indigenous resurgence in Kahnawà:ke. International Indigenous Policy Journal 6(3), 1-19. https://doi.org/10.18584/iipj.2015.6.3.6

Oguamanam, C. (2004). Indigenous peoples and international law: The making of a regime. Queen's Law Journal, 30, 348-399.

Oguamanam, C., \& Jain, V. (2017). Access and benefit sharing, Canadian and Aboriginal research ethics policy after the Nagoya Protocol: Digital DNA and transformations in biotechnology. Journal of Environmental Law and Practice, 3(1), 79-112. 
Oguamanam, C. (2018). ABS: Big data, data sovereignty and digitization: A new Indigenous research landscape. In C. Oguamanam, (Ed.), Genetic resources, justice and reconciliation: Canada and global access and benefits sharing (pp. 196-211). Cambridge University Press. https://doi.org/10.1017/9781108557122.012

Oguamanam, C. (2019). Indigenous data sovereignty: Retooling Indigenous resurgence for development. CIGI Papers No. 234. Centre for International Governance Innovation (CIGI).

Omwoyo, B. A. (2014). A critical evaluation of the regime for protection of Indigenous peoples' rights under international human rights law. https://www.academia.edu/11648613

Open African Innovation Research (Open AIR). (n.d.). [Website]. https://openair.africa/

Open Data Charter. (2015). International Open Data Charter. https://opendatacharter.net/ wp-content/uploads/2015/10/opendatacharter-charter F.pdf

Open North, \& British Columbia First Nations Data Governance Initiative (BCFNDGI). (2017). Decolonizing data: Indigenous data sovereignty primer. http://bcfndgi.squarespace.com/s/Decolonizing-Data-FN DATA SOVEREIGNTY PAPER.docx

Porro, N. M., Neto, J. S., \& Porro, R. (2015). Traditional communities as "subjects of rights" and the commoditization of knowledge in Brazil. International Indigenous Policy Journal, 6(2), 1-20. https://doi.org/10.18584/iipj.2015.6.2.8

Rainie, S. C., Kukutai, T., Walter, M., Figueroa-Rodriguez, O. L., Walker, J., \& Axelsson, P. (2019). Issues in open data: Indigenous data sovereignty. In T. Davies, S. Walker, M. Rubinstein, \& F. Perini (Eds.), The state of open data: Histories and horizons (pp. 300319). African Minds and International Development Research Centre (IDRC). https://www.idrc.ca/en/book/state-open-data-histories-and-horizons

Robinson, D. F. (2010). Confronting biopiracy: Challenges, cases and international debates. Routledge. https://doi.org/10.4324/9781849774710

Robinson, D. F. (2014). Biodiversity, access and benefit-sharing: Global case studies. Routledge. https://doi.org/10.4324/9781315882819

Robinson, D. F., Abdel-Latif, A., \& Roffe, P. (Eds.). (2017). Protecting traditional knowledge: The WIPO Intergovernmental Committee on Intellectual Property and Genetic Resources, Traditional Knowledge and Folklore. Routledge. https://doi.org/10.4324/9781315666358

Royal Commission on Aboriginal Peoples (RCAP).(1996). Report of the Royal Commission on Aboriginal Peoples. Report to the Government of Canada.

Santos, L. (2008). Genetic research in Native communities. Progress in Community Health Partnerships: Research, Education, and Action, 2(4), 321-327.

https://doi.org/10.1353/cpr.0.0046

Schultz, J. L., \& Rainie, S. C. (2014). The strategic power of data: A key aspect of sovereignty. International Indigenous Policy Journal, 5(4), 1-3.

https://doi.org/10.18584/iipj.2014.5.4.1

Smith, M. L., \& Seward, R. K. (Eds.). (2020). Making open development inclusive: Lessons from IDRC research. MIT Press and International Development Research Centre (IDRC). https://doi.org/10.7551/mitpress/11635.001.0001 
Snipp, C. M. (2016). What does data sovereignty imply: What does it look like? In T. Kukutai, \& J. Taylor (Eds.), Indigenous data sovereignty: Toward an agenda (pp. 39-55). ANU Press. https://doi.org/10.22459/CAEPR38.11.2016.03

Sterling, R. L. (2011). Genetic research among the Havasupai: A cautionary tale. AMA Journal of Ethics, 13(2), 113-117. https://doi.org/10.1001/virtualmentor.2011.13.2.hlaw1-1102

Traditional Knowledge Digital Library (TKDL). (n.d.). About TKDL. Council of Scientific and Industrial Research (CSIR), Government of India. http://www.tkdl.res.in/tkdl/ langdefault/common/Abouttkdl.asp?GL=Eng

UN. (1992). Convention on Biological Diversity. https:/www.cbd.int/doc/legal/cbd-en.pdf

UN. (2007a). United Nations Declaration on the Rights of Indigenous Peoples (UNDRIP), A/RES/61/295. https://www.un.org/development/desa/indigenouspeoples/declaration-on-the-rights-of-indigenous-peoples.html

UN. (2007b). Expert Mechanism on the Rights of Indigenous Peoples (EMRIP), UNHRC Res 6/36, UNHRCOR, Sixth Session. UN document A/HRC/6/36.

UN. (2010). Nagoya Protocol on Access and Benefit Sharing. https://www.cbd.int/abs/

UN. (2015). Transforming Our World: The 2030 Agenda for Sustainable Development, A/RES/70/1. https://sustainabledevelopment.un.org/post2015/transformingourworld/publication

UN General Assembly. (2014). Outcome Document of the High-Level Plenary Meeting of the General Assembly known as the World Conference on Indigenous Peoples, GA Resolution 69/2, UNGA 99th Session. Supplement No. 49, UN document A/ $\mathrm{RES} / 69 / 2$.

UN Permanent Forum on Indigenous Issues (UNPFII). (2004). Report of the workshop on data collection and disaggregation for indigenous peoples. For UNPFII Third Session, New York, 10-21 May. UN document E/C.19/2004/2. https://undocs.org/ E/C.19/2004/2

UNPFII. (2006). Report of the meeting on indigenous peoples and indicators of well-being. For UNPFII Fifth Session. UN document E/C.19/2006/CRP.3. https://www.un.org/ esa/socdev/unpfii/documents/workshop indic report.doc

Wilkinson, M., Dumontier, M., Aalbersberg, I. J., Appleton, G., Axton, M., Baak, A.... Mons, B. (2016). The FAIR guiding principles for scientific data management and stewardship. Scientific Data, 3, Article 160018. https://doi.org/10.1038/sdata.2016.18 